\title{
Assessing public perceptions about road lighting in five neighborhoods of Tirana, Albania
}

\author{
Kuenda Laze ${ }^{1}$ \\ ${ }^{1}$ Polytechnic University of Tirana, Faculty of Civil Engineering, Department of \\ Environmental Engineering, Rr. "M. Gjollesha", No. 54, 1023 Tirana, Albania
}

Received 21 February 2019, Accepted 09 September 2019

\begin{abstract}
Lighting is essential for sight, human health and well-being, emerging the need for assessing exterior lighting to better understand how far public is satisfied about exterior lighting. Participatory approach to assess public perceptions on road lighting in Tirana, Albania, is missing. Exterior lighting was assessed in five major roads of the capital city of Tirana, in November 2017 for education purposes using participatory approach and questionnaires. A road lighting assessment questionnaire was composed of sixteen questions to assess the perceived safety, pavement obstacle detection, visibility after-dark and road lighting related perceived satisfaction by public. Security, obstacle detection and visibility were evaluated using questionnaires for road lighting. The approximately 87 and 60 percent of respondents, respectively, were not able to detect a pavement obstacle afterdark and to distinguish a familiar face at a distance of $5 \mathrm{~m}$ and $10 \mathrm{~m}$ along roads. Road lighting after-dark was unsatisfactory to 60 percent of respondents. These findings identified road lighting could be inadequate for users, requiring further investigation and new data collection of road lighting in neighborhoods of Tirana.
\end{abstract}

Keywords: Road lighting, obstacle detection, Tirana, security, visibility, well-being

\section{Introduction}

Lighting is widely used in roads after the dark. Road lighting is applied for an expected benefit that is to provide pedestrians visibility, visual detection and recognition 'at a psychologically safe distance' [1].

Road lighting is strongly related to security in residential areas. It enables public to enhance their safety and perceived their safety and to recognize a facial expression [2]. Yang and Fotios [2] found that luminance and distance had significant effects on facial expression recognition for road lighting in residential areas; they estimated appropriate light levels for outdoor lighting by suggesting a minimum luminance of the face of a person from 0.1 to $1.0 \mathrm{~cd} / \mathrm{m}^{2}$, if a facial expression was to be identified accurately at $4 \mathrm{~m}$. Lighting of roads in residential areas is also important to detect a pavement obstacle and potential hazards contributing to reduced accident rates for pedestrians [3] and other road users. Data of Fotios and Uttley [3] suggested horizontal photopic illuminances of up to 0.9 lux for peripheral detection of a $10 \mathrm{~mm}$ obstacle at a distance of approximately $3.4 \mathrm{~m}$ ahead, in accordance with the scotopic/photopic ratio of the lighting and the observer age.

Road lighting should meet the recommended lighting standards that are applied by national or local governments (see e.g., [1]). However, there is also a need for asking public about public experience both in terms of road lighting data collection, road lighting data analysis and in terms of perceived satisfaction by public in relation to lighting in neighborhoods. Public satisfaction is important to be advised, because it potentially relates to public health and well-being considering that lighting is also a public health matter (see [4]). Evidences have shown that light enables vision and maintains health and well-being, respectively, through image-forming and the non-image forming effects [5], and this is also true for lighting having non-visual effects e.g., supporting circadian

\footnotetext{
${ }^{1}$ K. Laze, E-mail address : kuendalaze@gmail.com
} 
rhythms of a human body, which if it gets disrupted may lead to sleep disturbances, poor performance [1], obesity [6], breast cancer [7], [8], diabetes [9], cardiovascular disease [10] and metabolism disorders [11].

Survey data were collected for education purpose in Tirana, Albania. Survey was comprised of lighting assessments and questionnaire for assessing road lighting. Every student filled in the questionnaire to collect information about pedestrians' experience on road lighting regarding to pedestrians' perceived safety, pavement obstacle detection, visibility and pedestrians' perceived satisfaction. I aimed to investigate lighting assessment data using a descriptive statistics method and to show statistical significant results in this study.

There were fifteen road (exterior) lighting assessment questionnaires in total. A road lighting assessment questionnaire was composed of sixteen questions that was prepared (by the author) to assess the perceived safety [11], pavement obstacle detection [3], visibility and road lighting related perceived satisfaction by public. Questionnaire is not design to investigate any lighting and non-lighting factors and or road lighting performance in relation to perceived safety, pavement obstacle detection, visibility and perceived satisfaction. Road lighting assessment questionnaires were filled in immediately after the sunset following the day-dark approach [12], [13]. For simplicity, road lighting measurements were measured in lux and were compared to International Commission on Illumination (Comission International de l'Eclairage, (CIE)) (www.cie.co.at) standard of between 2 and 15 lux [14] for road lighting in urban areas. Minimum values, maximum values and average values of road lighting measurements were respectively shown for every road. The statistical significance ( $p$-value $\leq 0.05)$ results of $F$ test and $t$-test for pair of questions on pedestrians' safety, pavement obstacle detection, and visibility on road lighting were displayed.

\section{Materials and Methods}

\subsection{Survey}

The lighting assessment questionnaire was prepared by the author in compliance with the program of the Polytechnic University of Tirana and with the consent of students and conducted with the acceptance of participants (respondents and students). Questionnaires and road lighting measurements were conducted by fifteen master students of energy management profile at the Polytechnic University of Tirana, Albania, in November 2017. Before surveying, students were grouped into five groups (each group had three members) and were consulted on lighting measurements and on the questionnaire by the lecturer (the author). Every group of students was randomly assigned to assess lighting conditions in one of the selected roads.

Lighting measurements and questionnaires were newly conducted. Lighting was measured using Megaman LuxMeter (www.megaman.cc/resources/mobile-apps) installed in five mobile phones (each group used one mobile phone e.g., iPhone). Prior to lighting measurements, five mobile phones with installed Megaman LuxMeter were tested and were calibrated with the Hagner Universal Photometer S3 device in a laboratory. Hagner Universal Photometer S3 device is suitable for measurements in the field (www.hagner.se). Measurement errors produced by sensors of mobile phones were neglected in this study. Lighting assessment measurements were vertically and horizontally repeated every (a priory) $20 \mathrm{~m}$ at an approximately height of $1.5 \mathrm{~m}$ above the ground, along two side roads having a length of $12000 \mathrm{~m}$ in total (one side road length was approximately 1200 $\mathrm{m}$ ). The questionnaires were filled in immediately after-dark. Every student filled in a questionnaire (fifteen questionnaires in total) for the assigned road environment. All questionnaires were anonymous. 


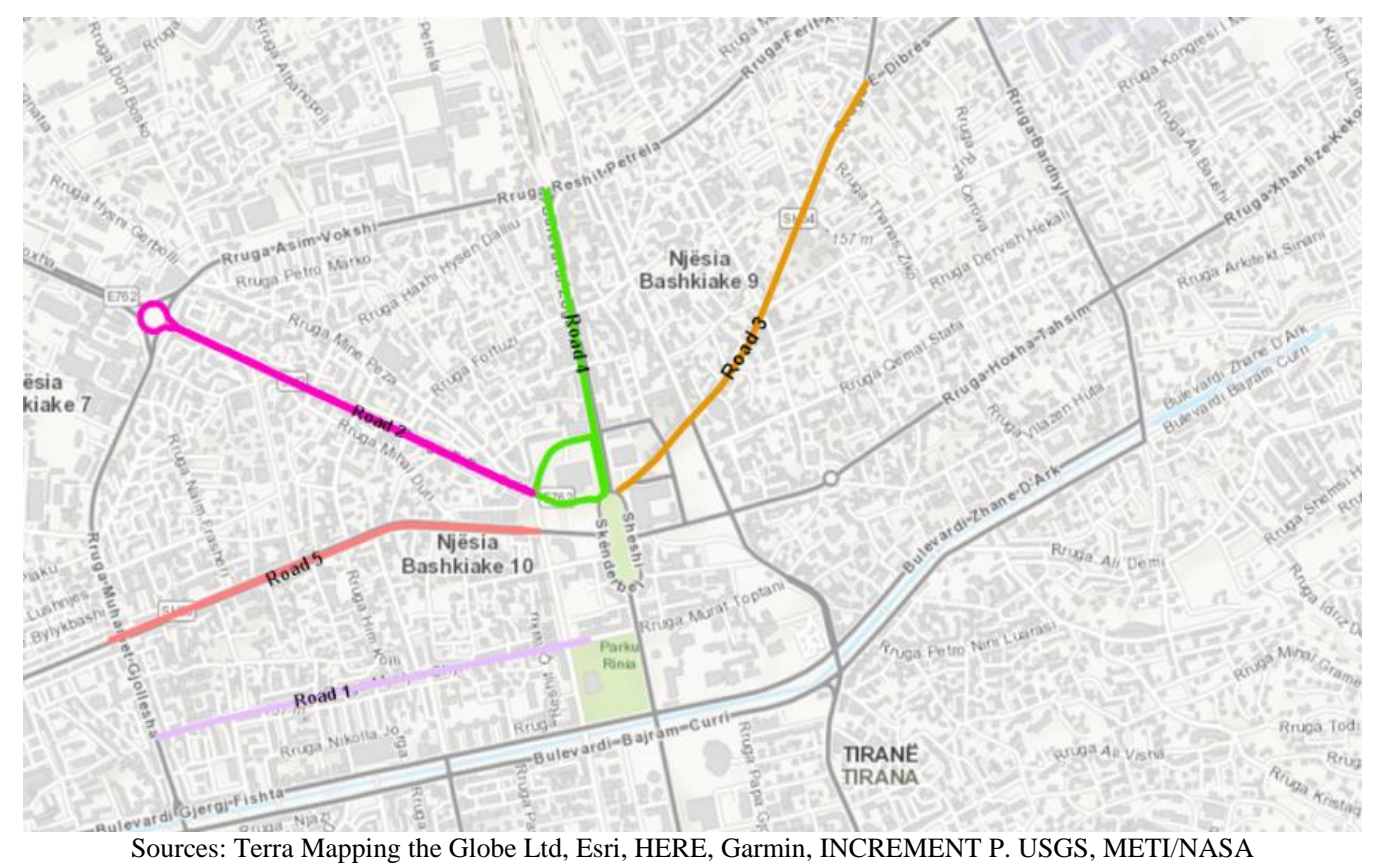

Fig 1. Road locations and segments in Tirana

\subsection{Questionnaire}

Five roads were two sided roads with two car lines, two pedestrian sides and one pedestrian side in the middle (roads 4 and 5). All roads are major urban streets (hereafter "roads") and located in Tirana. Road locations and segments (for lighting measurements) are shown in Fig. 1.

The questionnaire was composed of a set of questions that were prepared (by the author) concerning security (feeling safe, being accompanied by friends or not, meeting spot), obstacle detection (accident occurrence, tripping), visibility (distance) and general questions (respondent's house location, frequency of road use, age, lighting related perceived satisfaction and personal eyesight problems). In total, approximately 44, 19, 6 and 31 percent of questions were respectively related to security, obstacle detection, visibility and general questions. There were used more than one question on security to obtain consistent information and to better reduce any random error resulting from respondents' interpretation of the questions (e.g., three and twelve) and their rating [12] The questionnaires were manually filled in (including lighting measurements) approximately 120 minutes starting from the earliest time at 16:00 and ending at latest time at 19:30 in both road sides for five roads. Questionnaire is shown in S1.

Data analysis of all questionnaires was conducted in R programming (R Development Core Team, 2011). Ftest was used to analyze variance of lighting assessments for five roads. F-test is used, for example, to analyze variance of interior lighting assessments (see [15]). Statistical significance of the differences was calculated using paired t-tests. Questionnaire data were statistically analyzed to infer key-findings on road light use.

\section{Results}

Roads three, four and five had minimum lighting values close to CIE standard between 2 and 15 lux. Minimum and maximum lighting values were above CIE standard of above 2 lux in five roads, Table 1.

For each road, the largest difference between minimum and maximum (either horizontally or vertically) lighting values were found in roads number three and five. The horizontally lighting values were higher compared to vertically lighting values in 60 percent and 80 percent of roads. Car lights, bus lights and shop lighting contributed to large horizontally and vertically lighting values. Lamps failure or broken street lights contributed to low minimum lighting values e.g., road 3, (Table 1). I note here that lighting values are measured in different spots of roads (see 2.1 Survey). 
Table 1. Lighting measurements in five roads

\begin{tabular}{|c|c|c|c|c|}
\hline Roads & $\begin{array}{l}\text { Minimum } \\
\text { Horizontal }\end{array}$ & $\begin{array}{l}\text { Maximum } \\
\text { Horizontal }\end{array}$ & $\begin{array}{l}\text { Minimum } \\
\text { Vertical }\end{array}$ & $\begin{array}{c}\text { Maximum } \\
\text { Vertical }\end{array}$ \\
\hline [Number] & [Lux] & [Lux] & [Lux] & [Lux] \\
\hline 1 & 155.5 & 390 & 52.8 & 210.3 \\
\hline 2 & 102.4 & 319.3 & 23.3 & 196.1 \\
\hline 3 & 6.2 & 366.1 & 12.5 & 378.6 \\
\hline 4 & 11.4 & 278 & 16 & 227 \\
\hline 5 & 22.6 & 390 & 20.7 & 333.2 \\
\hline
\end{tabular}

Minimum horizontally and vertically lighting measurements and minimum and maximum vertically lighting measurements were highly correlated $(\rho>0.80$; Spearman rank correlation coefficient for a non-normal distribution of lighting data) F-test detected statistically significance $(\mathrm{p}=0.01)$ between minimum horizontally and vertically lighting measurements across road neighborhoods. The variances were not equal in 100 percent of responses for road lighting assessment. T-test showed that the percentage of responses did not statistically differ among lighting assessments for roads from one to five, (Table S2).
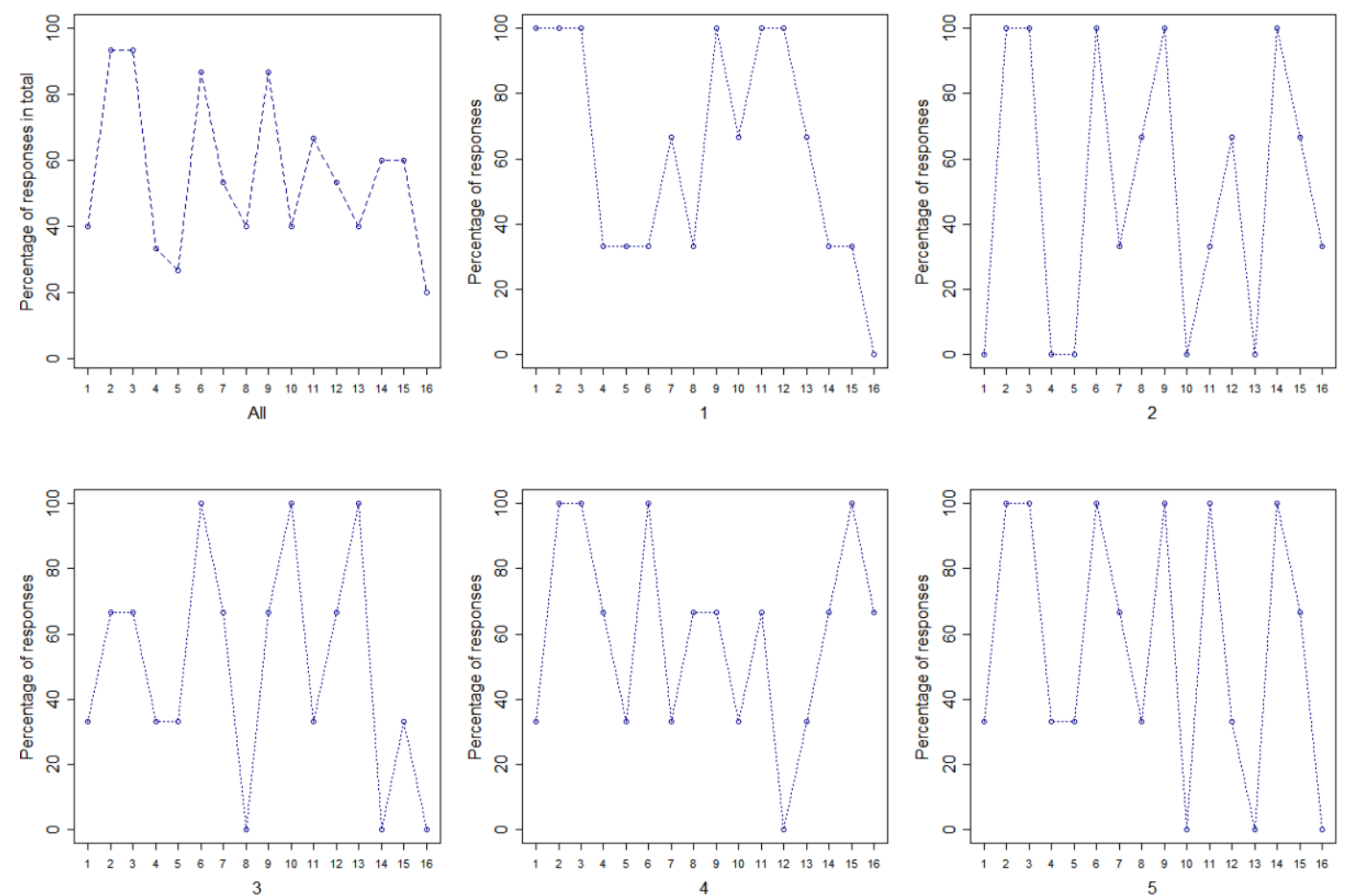

Fig.2. The percentage of responses of affirmative ("yes") responses in total (all roads; All) and for every road numbered from one to five.

In total, 60 and 40 percent of respondents were respectively between twenty and thirty and between thirty and sixty-five years old (question fifteen). The 40 percent of respondents were citizens working or studying nearby road neighborhoods. The 93, 93, 66 and 53 percent of respondents evaluated five roads as "safe" (questions number two, three, eleven and twelve at "All”) indicating relatively a high security after-dark in five road neighborhoods. In total, 53.3 and 40.0 percent of respondents had a pavement obstacle accident or a tripping and or had heard about other pedestrians' accidents or trippings (questions 7 and 8) due to pavement obstacles. The 86.6 percent of respondents experienced a pavement obstacle accident or a tripping after-dark (question 9). One or none of respondents could see at a distance $5 \mathrm{~m}$ and $10 \mathrm{~m}$ (question number ten) indicating a low visibility in 
60 percent of roads (numbered two, four and five). In total, 40 percent of respondents were satisfied by road lighting (question thirteen). None of respondents were satisfied by road lighting numbered two and five in Fig. 2. The unsatisfied respondents of 60 percent required an increased amount of road light (more lamps and or the replacement of low emitting light lamps).

\section{Discussion}

This work was to assess security, obstacle detection and visibility in roads neighborhoods in the urban area of Tirana, Albania. There were key findings on lighting visibility as perceived by respondents living in five road neighborhoods. Overall, roads were evaluated as "safe" by respondents (76 percent, in average, for five roads; Figure 2). A considerable number of respondents (above 40 percent) had experienced a pavement obstacle accident or a tripping after-dark or had heard about other pedestrians' accidents or tripping causing potential injuries to them indicating that road pavement can affect public health and health service. Pedestrians' accidents or tripping affected postal service workers in UK [16] and older people (above 60 years old) in the EU [17] causing injuries to them Respondents were able to comfortably see at small distance of $2 \mathrm{~m}$, but not at large distances of $5 \mathrm{~m}$ and $10 \mathrm{~m}$, indicating a low visibility to respondents in 60 percent of five roads. The distances $(2 \mathrm{~m}, 5 \mathrm{~m}, 10$ $\mathrm{m}$ ) also related to the luminance and distance effects for a familiar face detection and a face expression detection and a pavement obstacle detection. For example, eye tracking records proposed 'a tendency for obstacles to be detected approximately $3.4 \mathrm{~m}$ ahead' with a horizontal (photopic) illuminances of 0.90 lux [3]. Yang and Fotios [2] suggested the luminance from above $1.0 \mathrm{~cd} / \mathrm{m}^{2}$ for a facial identification at a distance of $10 \mathrm{~m}$, and the luminance of $1.0 \mathrm{~cd} / \mathrm{m}^{2}$ for a facial expression with a probability of 50 percent of a correct identification at a distance of $15 \mathrm{~m}$.

\subsection{Lighting is a public health and well-being matter}

This study showed that 60 percent of respondents asked for increased amount of light after-dark and 100 percent of respondents were unsatisfied in two roads (two and five; Figure 2), although all lighting measurement values were above the CIE standards of 2 lux. The need for increased amount of light by 60 percent of respondents showed that there could be needed road lighting improvements to meet public expectation on road lighting. The need for an increased amount of light after-dark coincides with a discussion for new road lighting standards [18] above existing road standard of between 2 lux and 15 lux of CIE. The need for increased amount of light could also be linked to the increased of the amount of light for pedestrians' immediate surroundings (see [19]).

Lighting is a public health and well-being issue [4]. Increased road lighting could help increase perceived satisfaction by public in relation to lighting and could also help increase the number of pedestrians and cyclists after-dark. For example, more people cycle and walk after- dark when roads were lit compared to when roads were unlit [20]. Uttley and Fotios [21] have found that the numbers of pedestrians and cyclists, respectively, increased by 62 percent and 38 percent during daylight conditions compared to after-dark conditions emphasizing the potential of road lighting (as a policy measure) to encourage walk and cycle after-dark. I note that walking of pedestrians and cycling are outdoor activities that are positively associated with positive public health outcomes and increased public well-being (see [22]).

\subsection{Limitations}

This study was limited to a small number of roads using a participatory approach. The questionnaire was also limited to a number of questions (16) and to a few questions with a point scale response (e.g., 1, 2), which could be used for an advance statistical analysis. The questionnaire was designed for education purposes to collect basic information on public perceptions in relation to security, pavement obstacle detection, and visibility for five major roads, excluding residential (minor) roads, which could have different lighting patterns and measurement values. There were also found differences between horizontally and vertically lighting value measurements. The horizontally and vertically lighting measurements could also be measured in residential roads to identify any lighting patterns. 
There were no data on lighting and perceived satisfaction by public in neighborhoods, potential public health outcomes and public well-being. There were no basic researches about relationships between road lighting and perceived security by public, public expectations for increased amount of light and pavement obstacle detection in Tirana.

\subsection{Future work}

Respondents and students participated in lighting assessment survey showing interests and willingness. This study showed that participatory approach could be applied for collecting lighting data in the future.

Respondents required an increased amount of light in their road neighborhoods and expressed their views about their perceived safety and perceived satisfaction in relation to road lighting. It was shown that a pavement obstacle accident or a tripping after-dark was an issue and should be further investigated because of health outcomes (injuries). Expectations of respondents about increased amount of light should also be explained because it could affect public health and well-being. For example, Uttley and Fotios [23] have found an increased risk to pedestrians using a designated crossing after-dark compared to pedestrians using a designated crossing during daylight, although, this increased risk was not due to the lack of road lighting. A careful data driven work could be used for explaining perceived satisfaction by public in neighborhoods, potential public health outcomes and public well-being in relation to exterior lighting. A database of lighting at global level is now released (lighttrends.lightpollutionmap.info), though, public perceptions on lighting change are of great importance as lighting change potentially affect public well-being.

\subsection{Lighting is a public good}

Lighting is a public good. There are evidences showing that interventions resulting to the changes in road lighting can affect public. For example, reduced street lighting incentives applied by local governments for the sake of energy saving and carbon emission reduction in England and Wales potentially negatively and positively affected well-being, because of public concern 'focused on road safety, fear of crime, mobility and seeing the night sky'([24]). Road lighting in neighborhoods is linked to public well-being and potential public health outcomes and to the right of public to have an adequate public good.

\section{Conclusions}

The understanding of public views about road lighting should be investigated, if this is not done yet, and or prior to any lighting installments and interventions. This would need lighting data to be collected in neighborhoods for explaining perceived satisfaction by public and public well-being in relation to exterior lighting.

\section{References}

[1] Rea, M. S. (2015). The lumen seen in a new light: Making distinctions between light, lighting and neuroscience. Lighting Research \& Technology, 47(3), 259-280.

[2] Yang, B., \& Fotios, S. (2015). Lighting and recognition of emotion conveyed by facial expressions. Lighting Research \& Technology, 47(8), 964-975.

[3] Fotios, S., \& Uttley, J. (2018). Illuminance required to detect a pavement obstacle of critical size. Lighting Research \& Technology, 50(3), 390-404.

[4] Pauley, S. M. (2004). Lighting for the human circadian clock: recent research indicates that lighting has become a public health issue. Medical hypotheses, 63(4), 588-596.

[5] Khademagha, P., Aries, M. B. C., Rosemann, A. L. P., \& Van Loenen, E. J. (2016). Implementing nonimage-forming effects of light in the built environment: A review on what we need. Building and Environment, 108, 263-272.

[6] Wyse, C. A., Selman, C., Page, M. M., Coogan, A. N., \& Hazlerigg, D. G. (2011). Circadian desynchrony 
and metabolic dysfunction; did light pollution make us fat?. Medical hypotheses, 77(6), 1139-1144.

[7] Rafnsson, V., Tulinius, H., Jónasson, J. G., \& Hrafnkelsson, J. (2001). Risk of breast cancer in female flight attendants: a population-based study (Iceland). Cancer Causes \& Control, 12(2), 95-101.

[8] Schernhammer, E. S., Kroenke, C. H., Laden, F., \& Hankinson, S. E. (2006). Night work and risk of breast cancer. Epidemiology, 17(1), 108-111.

[9] Pan, A., Schernhammer, E. S., Sun, Q., \& Hu, F. B. (2011). Rotating night shift work and risk of type 2 diabetes: two prospective cohort studies in women. PLoS medicine, 8(12), e1001141.

[10] Young, M. E., \& Bray, M. S. (2007). Potential role for peripheral circadian clock dyssynchrony in the pathogenesis of cardiovascular dysfunction. Sleep medicine, 8(6), 656-667.

[11] Stevens, R. G., Brainard, G. C., Blask, D. E., Lockley, S. W., \& Motta, M. E. (2013). Adverse health effects of nighttime lighting: comments on American Medical Association policy statement. American journal of preventive medicine, 45(3), 343-346.

[12] Fotios, S., Monteiro, A. L., \& Uttley, J. (2019). Evaluation of pedestrian reassurance gained by higher illuminances in residential streets using the day-dark approach. Lighting Research \& Technology, 51(4), 557-575.

[13] Fotios, S., \& Castleton, H. (2016). Specifying enough light to feel reassured on pedestrian footpaths. Leukos, 12(4), 235-243.

[14] Commission Internationale de l'Éclairage. (2010). Lighting of Roads for Motor and Pedestrian Traffic: CIE 115: 2010. CIE.

[15] Chraibi, S., Crommentuijn, L., van Loenen, E., \& Rosemann, A. (2017). Influence of wall luminance and uniformity on preferred task illuminance. Building and Environment, 117, 24-35.

[16] Bentley, T. A., \& Haslam, R. A. (2001). Identification of risk factors and countermeasures for slip, trip and fall accidents during the delivery of mail. Applied ergonomics, 32(2), 127-134.

[17] Feypell, V., Methorst, R., \& Hughes, T. (2012). Non-motor pedestrian accidents: a hidden issue. OECD International Transport Forum: Pedestrian Safety, Urban space and Health. Paris, OECD.

[18] Fotios, S., \& Gibbons, R. (2018). Road lighting research for drivers and pedestrians: The basis of luminance and illuminance recommendations. Lighting Research \& Technology, 50(1), 154-186.

[19] Haans, A., \& De Kort, Y. A. (2012). Light distribution in dynamic street lighting: Two experimental studies on its effects on perceived safety, prospect, concealment, and escape. Journal of Environmental Psychology, 32(4), 342-352.

[20] Fotios, S., Uttley, J., \& Fox, S. (2019). A whole-year approach showing that ambient light level influences walking and cycling. Lighting Research \& Technology, 51(1), 55-64.

[21] Uttley, J., \& Fotios, S. (2017). Using the daylight savings clock change to show ambient light conditions significantly influence active travel. Journal of Environmental Psychology, 53, 1-10.

[22] Tsouros, P. E. (2008). A healthy city is an active city: a physical activity planning guide. The Regional Office for Europe of the World Health Organization, Denmark, 9.

[23] Uttley, J., \& Fotios, S. (2017). The effect of ambient light condition on road traffic collisions involving pedestrians on pedestrian crossings. Accident Analysis \& Prevention, 108, 189-200.

[24] Green, J., Perkins, C., Steinbach, R., \& Edwards, P. (2015). Reduced street lighting at night and health: a rapid appraisal of public views in England and Wales. Health \& place, 34, 171-180.

\section{Supplementary material}

S1: Questionnaire

\begin{tabular}{|c|c|c|}
\hline No. & Questions & Response[Yes, No] \\
\hline $1 G$ & Do you live around here or do you pass by? & \\
\hline $2 S$ & Do you often use this road, please? & \\
\hline $3 S$ & $\begin{array}{l}\text { If yes, what is the reason you often use this road? This is because: } \\
\text { 1. You have your house near here/You work or study nearby } \\
\text { 2. The road lighting is adequate } \\
\text { 3. This road is safe } \\
\text { 4. This road is well-paved }\end{array}$ & \\
\hline
\end{tabular}


No.

Questions

\begin{tabular}{|c|c|}
\hline $4 S$ & Do you walk with your children, in the evening? \\
\hline $5 S$ & If not, why don't you walk with your children in the evening, please? \\
\hline $6 \mathrm{~S}$ & Do you walk alone or with your friends? \\
\hline $70 D$ & $\begin{array}{l}\text { Generally speaking, have you ever had any accident, tripping on this } \\
\text { road (falling) due to pavement obstacles? }\end{array}$ \\
\hline $80 D$ & $\begin{array}{l}\text { If not, have you ever heard about other pedestrians to have any } \\
\text { accident, tripping while walking on this road, please? }\end{array}$ \\
\hline $90 D$ & $\begin{array}{l}\text { Have you ever had a pavement obstacle accident or tripping on this } \\
\text { road, after the sunset? }\end{array}$ \\
\hline \multirow[t]{4}{*}{$10 \mathrm{~V}$} & $\begin{array}{l}\text { Are you able to distinguish your friends or your family members' faces } \\
\text { at distance of: }\end{array}$ \\
\hline & $\square \quad 2 \mathrm{~m}$ \\
\hline & $\square \quad 5 \mathrm{~m}$ \\
\hline & $\square \quad 10 \mathrm{~m}$ far from you, please? \\
\hline $11 S$ & $\begin{array}{l}\text { Have you ever had a meeting place on this road with your friends or } \\
\text { your family members? }\end{array}$ \\
\hline $12 S$ & $\begin{array}{l}\text { Do you feel safe while yo } \\
\text { 1. I feel unsafe } \\
\text { 2. I feel somehow safe } \\
\text { 3. I feel adequately safe } \\
\text { 4. I feel safe } \\
\text { 5. I feel fully safe }\end{array}$ \\
\hline $13 G$ & Are you satisfied by this road lighting? \\
\hline $14 \mathrm{G}$ & If not, what do you suggest to improve the road lighting, please? \\
\hline \multirow[t]{5}{*}{$15 G$} & Are you: \\
\hline & $\square \quad$ below 30 years old \\
\hline & $\square \quad$ between 30 and 45 years old \\
\hline & $\square \quad$ between 45 and 65 years old \\
\hline & $\square \quad$ above 65 years old \\
\hline
\end{tabular}

$16 \mathrm{G} \quad$ Do you have any eyesight problems, please?

Note: $\mathrm{S}=$ Security, $\mathrm{OD}=$ Obstacle Detection, $\mathrm{V}=$ Visibility, $\mathrm{G}=$ General question

Table S2. The statistically significant F-test and t-test results for lighting assessments and pairs of affirmative responses ("yes")(in percentage) given by respondents for every road numbered from one to five. The percentage of affirmative responses ("yes") given by respondents for every road numbered from one to five are shown in Figure 2. Variable is the percentage of affirmative responses ("yes") given by respondents for every road numbered from one to five. $\operatorname{Road} 1$ is road $1, \operatorname{road} 2$ is $\operatorname{road} 2, \operatorname{road} 3$ is road $3, \operatorname{road} 4$ is $\operatorname{road} 4, \operatorname{road} 5$ is road 5. Roads are shown in Figure 1.

\begin{tabular}{cccccccc} 
Roads & Variables & F-test & df & p-value & t-test & df & p-value \\
\hline & road1_road2 & 0.65 & 15 & 0.42 & 0.92 & 28.7 & 0.36 \\
\hline road1_road3 & 0.98 & 15 & 0.97 & 1.03 & 293.9 & 0.31 \\
\hline
\end{tabular}




\begin{tabular}{cccccccc}
\hline & road1_road4 & 1.26 & 15 & 0.65 & 0.18 & 29.5 & 0.85 \\
\hline & road1_road5 & 0.73 & 15 & 0.55 & 0.47 & 29.3 & 0.63 \\
\hline road2_road3 & 1.49 & 15 & 0.44 & 0 & 28.8 & 1 \\
\hline road2_road4 & 1.92 & 15 & 0.21 & -0.8 & 27.2 & 0.42 \\
\hline road2_road5 & 1.11 & 15 & 0.83 & -0.43 & 29.9 & 0.67 \\
\hline road3_road4 & 1.28 & 15 & 0.63 & -0.9 & 29.5 & 0.37 \\
\hline $\begin{array}{c}\text { Lighting } \\
\text { measurements }\end{array}$ & road3_road5 & 0.74 & 15 & 0.57 & -0.47 & 29.3 & 0.63 \\
\hline & road4_road5 & 0.58 & 15 & 0.3 & 0.33 & 28 & 0.74 \\
\hline & max_horiz max- & 0.35 & 4 & 0.34 & 1.87 & 6.5 & 0.1 \\
\hline
\end{tabular}

Note: p-value below or equal with 0.05 is in bold. 